\title{
Impulsively Started Horizontal Riga Plate Embedded in Unsteady Casson Fluid Flow with Rotation
}

\author{
Sonia Nasrin ${ }^{*}$, Rabindra Nath Mondal', Md. Mahmud Alam² \\ ${ }^{1}$ Department of Mathematics, Jagannath University, Dhaka, Bangladesh \\ ${ }^{2}$ Mathematics Discipline, Khulna University, Khulna, Bangladesh \\ Email: ^sn_mri@yahoo.com,rnmondal71@yahoo.com, alam_mahmud2000@yahoo.com
}

How to cite this paper: Nasrin, S., Mondal, R.N. and Alam, Md.M. (2020) Impulsively Started Horizontal Riga Plate Embedded in Unsteady Casson Fluid Flow with Rotation. Journal of Applied Mathematics and Physics, 8, 1861-1876.

https://doi.org/10.4236/jamp.2020.89140

Received: August 10, 2020

Accepted: September 18, 2020

Published: September 21, 2020

Copyright (c) 2020 by author(s) and Scientific Research Publishing Inc. This work is licensed under the Creative Commons Attribution International License (CC BY 4.0).

http://creativecommons.org/licenses/by/4.0/

\begin{abstract}
This article is based on the impulsively started horizontal Riga plate in two dimensional unsteady Casson fluid flows with rotation. The plate starts abruptly from the rest relative to the rotating fluids moving with uniform acceleration in its plane. Numerical solutions are acquired by using explicit finite difference method and estimated results have been gained for various values of the Rotational parameter, modified Hartmann number, Prandtl number, Radiative parameter, Eckert number, Heat source parameter, Schmidt number, and the Soret number. Both the Compaq visual FORTRAN 6.6a and MATLAB R2015a tools have been used to find the numerical solutions and the graphical presentation. The Skin friction, Nusselt number and Sherwood number have been computed and the effects of some pertinent parameters on various distributions are discussed briefly and presented graphically.
\end{abstract}

\section{Keywords}

Casson Fluid, Riga Plate, Explicit Finite Difference and Rotation

\section{Introduction}

Casson fluid flows along the Riga plate create a new research area that plays a fundamental role in various industrial and engineering processes, such as MHD generators, thermal nuclear reactors, flow meters and the design of nuclear reactors. Such flows have tremendous applications in civil engineering, mechanical engineering, chemical engineering, food processing and biomechanics. Riga plate is generated by the combination of electrodes and permanent magnets that 
create a plane surface instead of polarity and magnetization. The flow of Casson fluids with heat transfer is widely used in the processing of chocolate, foams, syrups, toffee and food processing industries. The Riga plate is first induced by Gailitis and Leilausis [1] to generate a wall paralleled Lorentz force to control the fluid flow. Anjum et al. [2] explained the thermally stratified viscous fluid with stagnation point flow dominated by a variable thicked non-linear Riga plate. Ahmed et al. [3] studied the united convection boundary layer flows of a nanofluid along a Riga plate stated vertically with strong suction. The study of a nanofluid flow past a vertical convective heated Riga plate is analyzed by Wahidunnisa et al. [4]. The characteristics of nanofluid boundary layer flow occupied with a Riga plate is concerned by Hayat et al. [5]. Pantokratoras and Magyari [6] proposed an electro-magneto hydrodynamic free convection flow of a weakly conducting fluid from an electromagnetic actuator or Riga plate. Thereafter Pantokratoras [7] investigated the Riga-plate moves with constant velocity or the Riga-plate is situated in a constant free stream. Iqbal et al. [8] investigated the boundary layer Casson fluid flow for a stagnation point along a Riga plate. The incompressible, steady and electrically conducting non-Newtonian Casson fluid flow among two cylinders, where a magnetic field is applied radially is studied by Eldabe et al. [9]. Hydrodynamic impulsively lid-driven flow with heat transfer of a Casson fluid has been described by Attia and Sayed [10]. Hayat et al. [11] analyzed the MHD Casson fluid flow of the Soret and Dufour effects upon a stretched surface. Ramesh and Devakar [12] have considered three fundamental flows Couette, Poiseuille and generalized Couette flow of an incompressible Casson fluid between parallel plates with slip boundary conditions. Mahantesh et al. [13] have considered a two-dimensional flow of non-Newtonian MHD flow of Casson fluid. Raju et al. [14] analyzed the heat source and chemical reaction effect on Casson fluid flow past an exponentially enterable stretching surface with thermal radiation and viscous dissipation. Rao and Sreenadh [15] investigated the steady two-dimensional MHD convective boundary layer Casson fluid flow over an exponentially inclined permeable stretching surface with thermal radiation and chemical reaction. Saidulu and Lakshmi [16] presented the heat and mass transfer boundary layer fluid flow of a non-Newtonian Casson fluid towards a porous stretching sheet with thermal radiation and suction. The Casson fluid flow with heat transfer and thermal radiation along a porous stretching surface is presented by Pramanik [17]. Ahmad [18] described the effect of the Powell-Eyring and Reiner-Phillipoff fluid flow on the Riga plate. Yucel [19] explained the associated free convection flow in a micropolar fluid through a Riga plate. Ghulam Rasool et al. [20] investigated the effect of a chemical reaction of nanofluids in the presence of Lorentz force and thermal radiation.

From the above-mentioned discussion of the authors, we have come to a completely new opinion that has not discussed yet before. The royal object is to investigate the behavior of the fluid particles which are adjacent with an impul- 
sively started horizontal Riga plate in Casson fluid flow where appearance a rotation. Numerical investigations are gained by the finite difference method and its solutions are computed by using the code of Compaq visual FORTRAN 6.6a and also MATLAB R2015a.

\section{Problem Formulation}

Consider the horizontal Riga plate in laminar, incompressible Casson fluid flows, which is parallel to the $x$-axis, and the $y$-axis is normal to it (Figure 1 ). Also, consider the system rotated about a vertical axis with angular velocity $\Omega$. Initially, both the plate and fluid are stagnant. At $t=0$ the plate is set in motion at a constant velocity $U_{0}$ in the direction of $x$-axis. This generates a two dimensional parallel flows near the plate. Instantaneously at time $t>0$ the temperature of the plate and concentration are raised from $T_{w}$ to $T_{\infty}$ and $C_{w}$ to $C_{\infty}$ respectively, which are thereafter sustained. Here $T_{w}, C_{w}$ are temperature and concentration at the wall and $T_{\infty}, C_{\infty}$ designate the temperature and concentration outside the boundary layer. Due to the Riga plate, the Lorentz force is defined as $\bar{f}=\boldsymbol{J} \wedge \boldsymbol{B} \approx \sigma(\boldsymbol{E} \wedge \boldsymbol{B})$, which generates magnetic force. According to the Grinberg investigation, this magnetic force is defined as follows:

$$
\bar{f}=\boldsymbol{J} \wedge \boldsymbol{B}=\left(\frac{\pi}{8} J_{0} M_{0} \mathrm{e}^{-\frac{\pi}{l} y}, 0, \frac{\pi}{8} J_{0} M_{0} \mathrm{e}^{-\frac{\pi}{l} y}\right)
$$

where, $J_{0}$ is the applied current density, $M_{0}$ is the magnetization of the permanent magnets and $l$ is the width of magnets and electrodes.

The fundamental equation of Casson fluid can be written as

$$
\tau_{i j}=\left\{\begin{array}{l}
2\left(\mu_{b}+\frac{p_{y}}{\sqrt{2 \pi}}\right) e_{i j} \quad \text { when } \pi>\pi_{c} \\
2\left(\mu_{b}+\frac{p_{y}}{\sqrt{2 \pi_{c}}}\right) e_{i j} \text { when } \pi<\pi_{c}
\end{array}\right.
$$

where $\tau$ is the shear stress, $\mu_{b}$ is known as plastic viscosity of the non-Newtonian
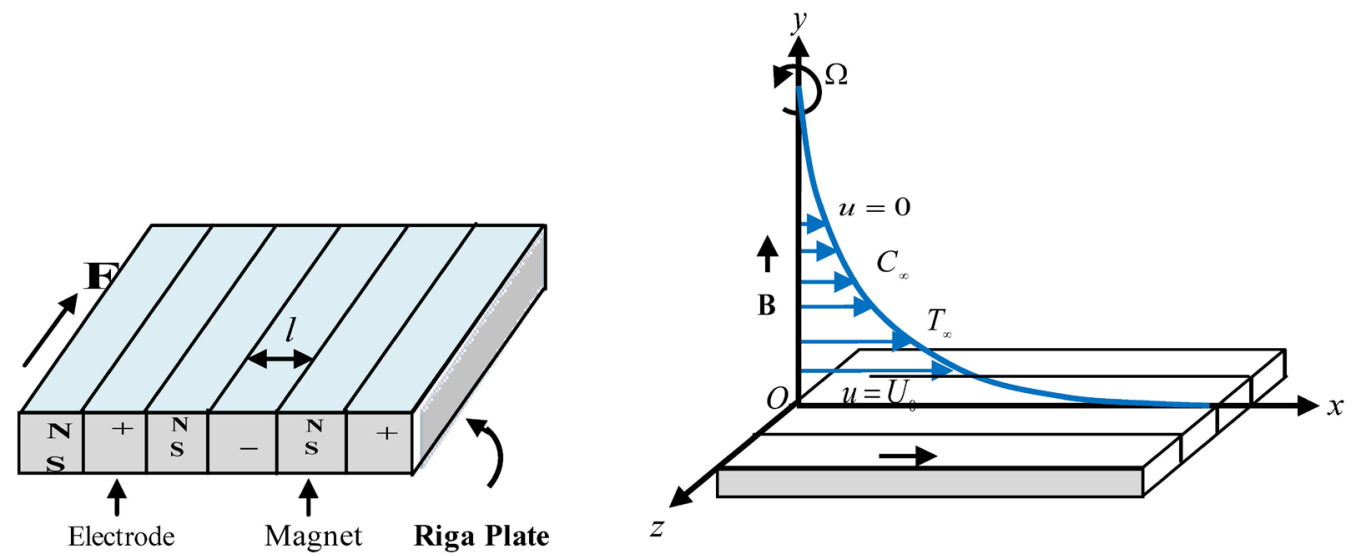

Figure 1. Physical configuration. 
fluid, $p_{y}$ is known as yield stress of the fluid, mathematically expressed as $p_{y}=\mu_{b} \sqrt{2 \pi} / \beta$, where $\beta$ is the parameter of the Casson fluid, $\pi=e_{I J} e_{I J}$, (i.e. $\pi$ is the product of the component of deformation rate with itself, here $e_{I J}$ is the $(i, j)$ th component of deformation rate), $\pi_{c}$ is the critical value based on the non-Newtonian model. Dynamic viscosity of Casson fluid is defined as $\mu=\mu_{b}+p_{y} / \sqrt{2 \pi}$ so that kinematic viscosity may define as $v=v_{b}(1+1 / \beta)$ where $v_{b}=\mu_{b} / \rho$.

Within the framework of the above assumptions, the equations related to the unsteady two-dimensional problems governed by the following system of coupled non-linear partial differential equations under the boundary layer approximations, are given as follows:

$$
\begin{gathered}
\frac{\partial u}{\partial x}+\frac{\partial v}{\partial y}=0 \\
\frac{\partial u}{\partial t}+u \frac{\partial u}{\partial x}+v \frac{\partial u}{\partial y}=v_{b}\left(1+\frac{1}{\beta}\right) \frac{\partial^{2} u}{\partial y^{2}}+\frac{\pi}{8 \rho} J_{0} M_{0} \mathrm{e}^{-\frac{\pi}{l} y}-2 w \Omega_{0} \\
\frac{\partial w}{\partial t}+u \frac{\partial w}{\partial x}+v \frac{\partial w}{\partial y}=v_{b}\left(1+\frac{1}{\beta}\right) \frac{\partial^{2} w}{\partial y^{2}}+\frac{\pi}{8 \rho} J_{0} M_{0} \mathrm{e}^{-\frac{\pi}{l} y}+2 u \Omega_{0} \\
\frac{\partial T}{\partial t}+u \frac{\partial T}{\partial x}+v \frac{\partial T}{\partial y} \\
\frac{k}{\rho C_{p}} \frac{\partial^{2} T}{\partial y^{2}}-\frac{1}{\rho C_{p}} \frac{16 \sigma^{*} T_{\infty}^{3}}{3 k^{*}} \frac{\partial^{2} T}{\partial y^{2}}+\frac{v_{b}}{C_{p}}\left(1+\frac{1}{\beta}\right)\left[\left(\frac{\partial u}{\partial y}\right)^{2}+\left(\frac{\partial w}{\partial y}\right)^{2}\right]-\frac{Q}{\rho C_{p}}\left(T-T_{\infty}\right) \\
\frac{\partial C}{\partial t}+u \frac{\partial C}{\partial x}+v \frac{\partial C}{\partial y}=D_{m} \frac{\partial^{2} C}{\partial y^{2}}+D_{T} \frac{\partial^{2} T}{\partial y^{2}}
\end{gathered}
$$

And the corresponding boundary conditions for the problem are given as follows:

$$
\begin{aligned}
& u=U_{0}, w=0, T=T_{w}, C=C_{w} \text { at } y=0 \\
& u=0, w=0, T=T_{\infty}, C=C_{\infty} \text { at } y \rightarrow \infty
\end{aligned}
$$

Here, $x$ and $y$ are the Cartesian coordinates systems, $u$ and $w$ are the velocity in the $x$ and $y$ direction respectively, $C_{p}$ is the specific heat at the constant pressure, $Q$ is the variable heat source parameter, $\rho$ is the density of the fluid, $k$ is thermal conductivity, $v_{b}$ is the kinematic viscosity, $D_{m}$ is the mass diffusivity, $D_{T}$ is the coefficient of the thermal diffusivity and $\beta=\frac{\mu_{b} \sqrt{2 \pi}}{p_{y}}$ is the Casson fluid parameter.

\section{Similarity Analysis}

Now introducing the non-dimensional variables and the necessary transformations are as follows: 


$$
\begin{aligned}
& x^{*}=\frac{x}{h}, y^{*}=\frac{y}{L}, u^{*}=\frac{u}{U_{0}}, w^{*}=\frac{w}{U_{0}}, t^{*}=\frac{t U_{0}}{h}, \theta=\frac{T-T_{\infty}}{T_{w}-T_{\infty}}, \\
& \varphi=\frac{C-C_{\infty}}{C_{w}-C_{\infty}}, h=\frac{L^{2} U}{v_{b}}, L=\frac{l}{\pi}, U_{0}=\frac{v_{b}}{l}
\end{aligned}
$$

Using these quantities into the Equations (1)-(6), removing asterisk sign it is found the dimensionless form of the equations are as follows:

$$
\begin{gathered}
\frac{\partial u}{\partial x}+\frac{\partial u}{\partial y}=0 \\
\frac{\partial u}{\partial t}+u \frac{\partial u}{\partial x}+v \frac{\partial u}{\partial y}=\left(1+\frac{1}{\beta}\right) \frac{\partial^{2} u}{\partial y^{2}}+H_{a} \mathrm{e}^{-y}-R w \\
\frac{\partial w}{\partial t}+u \frac{\partial w}{\partial x}+v \frac{\partial w}{\partial y}=\left(1+\frac{1}{\beta}\right) \frac{\partial^{2} w}{\partial y^{2}}+H_{a} \mathrm{e}^{-y}+R u \\
\frac{\partial \theta}{\partial t}+u \frac{\partial \theta}{\partial x}+v \frac{\partial \theta}{\partial y}=\frac{1+Q_{r}}{P_{r}} \frac{\partial^{2} \theta}{\partial y^{2}}+E_{c}\left(1+\frac{1}{\beta}\right)\left[\left(\frac{\partial u}{\partial y}\right)^{2}+\left(\frac{\partial w}{\partial y}\right)^{2}\right]-Q_{s} \theta \\
\frac{\partial \varphi}{\partial t}+u \frac{\partial \varphi}{\partial x}+v \frac{\partial \varphi}{\partial y}=\frac{1}{S_{c}} \frac{\partial^{2} \varphi}{\partial y^{2}}+S_{0} \frac{\partial^{2} \theta}{\partial y^{2}}
\end{gathered}
$$

With the boundary conditions:

$$
\begin{aligned}
& u=1, w=0, \theta=1, \varphi=1 \quad \text { at } y=0 \\
& u=0, w=0, \theta=0, \varphi=0 \text { at } y \rightarrow \infty
\end{aligned}
$$

where, $H_{a}=\frac{\pi J_{0} M_{0} h}{8 \rho U_{0}^{2}}$ is the Modified Hartmann number; $R=\frac{2 l^{2} \Omega_{0}}{\pi^{2} v_{b}}$ is the Rotational parameter; $P_{r}=\frac{\rho C_{p} v_{b}}{k}$ is the Prandtl number ; $Q_{r}=\frac{16 \sigma^{*} T_{\infty}^{3}}{3 k^{*} k}$ is the Radiative parameter; $E_{c}=\frac{h v_{b} U_{0}}{c_{p} L^{2}\left(T_{w}-T_{\infty}\right)}$ is the Eckert number;

$Q_{s}=\frac{Q v_{b}}{\rho C_{p} V_{0}^{2}}$ is the Heat source parameter; $S_{c}=\frac{v_{b}}{D_{m}}$ is the Schmidt number ; $S_{0}=\frac{D_{T}}{v_{b}} \frac{\left(T_{w}-T_{\infty}\right)}{\left(C_{w}-C_{\infty}\right)}$ is the Soret number.

\section{Method of Solution}

The governing non-linear coupled dimensionless form of partial differential Equations (6) to (10) with the associated initial and boundary conditions (11) are solved. In fact for this set of equations, it is not possible to find its exact solution and hence it has been calculated these equations by using the explicit finite difference method. The finite difference schemes with respect to $t, x$ and $y$ are as follows:

$$
\begin{aligned}
& \frac{\partial u}{\partial t}=\frac{U_{i, j}^{k+1}-U_{i, j}^{k}}{\Delta y} ; \frac{\partial u}{\partial x}=\frac{U_{i, j}^{k}-U_{i-1, j}^{k}}{\Delta x} ; \frac{\partial u}{\partial y}=\frac{U_{i, j}^{k}-U_{i, j-1}^{k}}{\Delta y} ; \\
& \frac{\partial^{2} u}{\partial y^{2}}=\frac{U_{i, j+1}^{k}-2 U_{i, j}^{k}+U_{i, j-1}^{k}}{\Delta y^{2}} ; \frac{\partial^{2} H}{\partial t^{2}}=\frac{h_{i, j}^{k+2}-2 h_{i, j}^{k+1}+h_{i, j}^{k}}{\Delta t^{2}}
\end{aligned}
$$


Here, the subscripts $i$ and $j$ refer to $x$ and $y$ and the superscript $k$ refers to time $t$. Same way it has been followed for the other variables. The graphical solutions of the program are illustrated by using both the Compaq visual FORTRAN 6.6a and MATLAB R2015a tools.

\section{Skin Friction, Nusselt Number and Sherwood Number}

The effects of various parameters on local and average shear stress from the velocity profile have been investigated. The velocity gradient at the plate is defined as the shear stress; the non-dimensional form of the local shear stress and average shear stress in $x$-direction is given by the relations $\tau_{L}=\left.\mu \frac{\partial u}{\partial y}\right|_{y=0}$ and $\tau_{A}=\left.\frac{1}{L} \int_{0}^{L} \mu \frac{\partial u}{\partial y}\right|_{y=0} \mathrm{~d} x$ respectively. From the temperature profile, the effects of various parameters on local and average Nusselt number have been calculated. The rate of heat transfer at the plate is defined as the Nusselt number; the local Nusselt number and the average Nusselt number are given by $N u_{L}=-\left.\mu \frac{\partial \theta}{\partial y}\right|_{y=0}$ and $N u_{A}=-\left.\frac{1}{L} \int_{0}^{L} \mu \frac{\partial \theta}{\partial y}\right|_{y=0} \mathrm{~d} x$ respectively. Similarly, the effects of various parameters on local and average Sherwood number from the concentration field have been analyzed. The rate of mass transfer at the plate is defined as the Sherwood number; the local Sherwood number and the average Sherwood number is defined by $S h_{L}=-\left.\mu \frac{\partial \varphi}{\partial y}\right|_{y=0}$ and $S h_{A}=-\left.\frac{1}{L} \int_{0}^{L} \mu \frac{\partial \varphi}{\partial y}\right|_{y=0} \mathrm{~d} x$ respectively.

\section{Results and Discussion}

The behavior of the primary velocity $(u)$, the secondary velocity $(w)$, temperature $(\theta)$ and concentration distributions $(\varphi)$ have been analyzed for the different values of Rotational parameter $(R)$, modified Hartmann number $\left(H_{a}\right)$, Prandtl number $\left(P_{r}\right)$, Radiative parameter $\left(Q_{r}\right)$, Eckert number $\left(E_{c}\right)$, Heat source parameter $\left(Q_{s}\right)$, Casson fluid parameter $(\beta)$, Schmidt number $\left(S_{c}\right)$ and the Soret number $\left(S_{0}\right)$. Consider the values of $H_{a}=1.0, P_{r}=0.71, R=0.2$, $Q_{r}=0.5, Q_{s}=1.0, E_{c}=0.01, S_{c}=0.6, S_{0}=1.0$ and $\beta=2.0$ are fixed as common for all cases except the varied values of respective parameter. The flow characteristics are shown graphically from Figures 2-19.

\subsection{Mesh and Time Sensitivity Test}

To find the steady-state solution of our problem, the computations have been carried out for different mesh pairs (Figure 2(a)). It has been shown that there are negligible changes for the mesh pairs $(m, n)=(70,70),(m, n)=(80,80)$ and $(m, n)=(90,90)$. Also Figure $2(\mathrm{~b})$ depicts that the velocity distributions for the different time $\tau=1,2,3,6,7$ and 8 with the time increment $\Delta t=0.001$ 
with mesh pair $(m, n)=(80,80)$. It is observed that after $t=6$, there is very minimal change in the velocity distribution. Hence from both figures that there is a suitable choice of maximum time $t=6$ and mesh pair $(m, n)=(80,80)$ with time increment $\Delta t=0.001$ for steady-state solution.

\subsection{Code Sensitivity Test}

To verify the results, the computations data are collected by using Compaq visual FORTRAN 6.6a and MATLAB R2015a tools on the velocity distributions with the increasing values of the Casson parameter $(\beta)$ and its graphical representations are shown in Figure 3(a) and Figure 3(b) respectively. Here it is found that the velocity decreases with the increases of $\beta$. The same results have found in both codes.

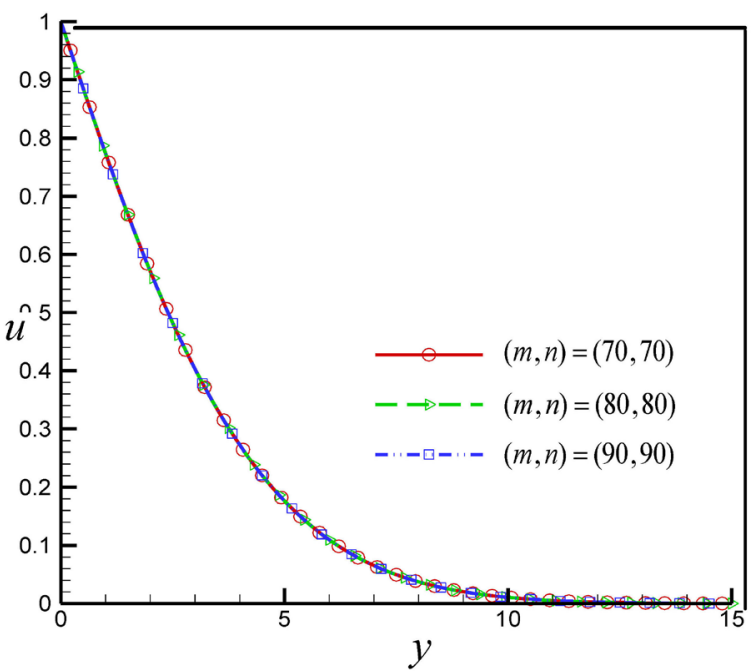

(a)

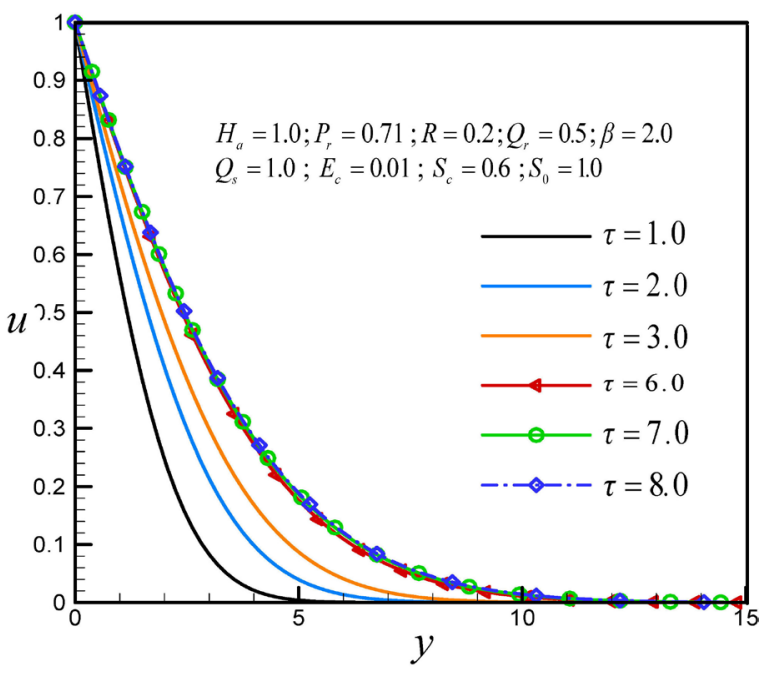

(b)

Figure 2. (a) Mesh sensitivity on primary velocity $u$; (b) Time sensitivity on primary velocity $u$.

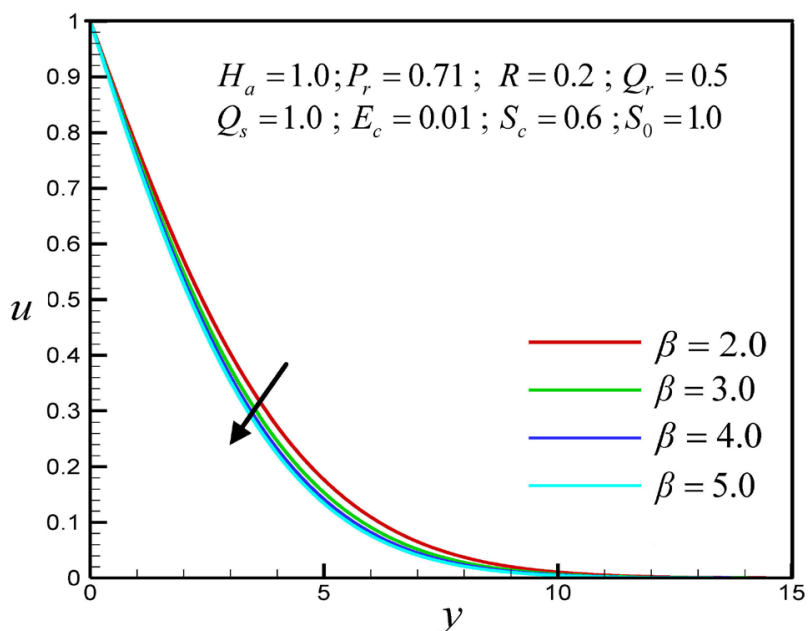

(a)

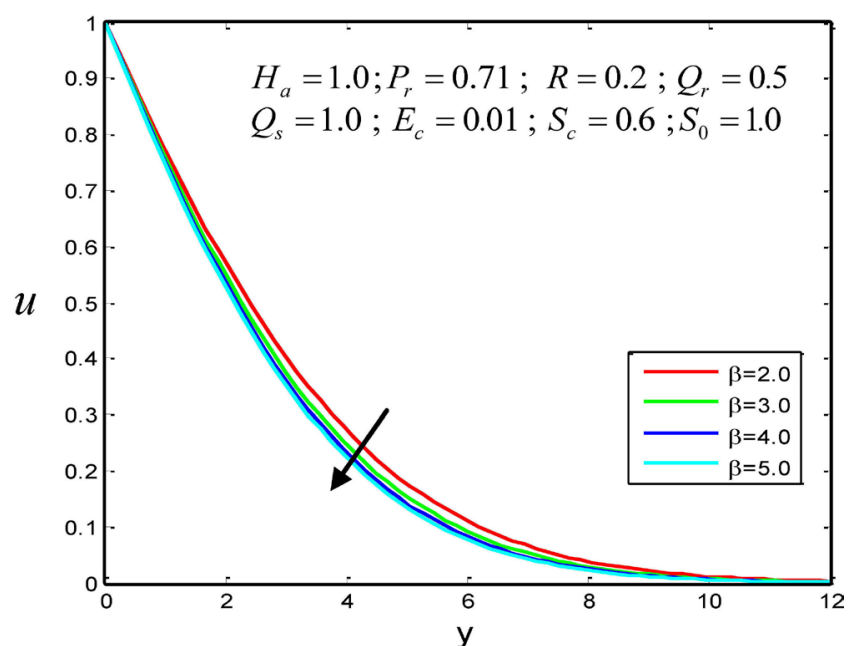

(b)

Figure 3. (a) Primary velocity distribution for $u$ for different values of $\beta$ [Fortran code]; (b) Primary velocity distribution $u$ for different values of $\beta \quad$ [Matlab code]. 


\subsection{Primary Velocity Distribution}

It is seen from Figure 4 that the nature of fluid velocity for the variation of the Hartmann number, there are very negligible changes in the primary velocity distributions with the increase of $H_{a}$, which is shown in enlarge figure in Figure 4. Figure 5 represents the influence of the rotational parameter $(R)$ on the primary velocity is decreased with the increase of $R$.

\subsection{Secondary Velocity Distribution}

It is noticed from Figure 6, with the increasing values of the Casson fluid parameter $(\beta)$, the secondary velocity $w$ has minor increasing flow near the plate and thereafter it has decreasing flow. It is observed from Figure 7 that $w$ has been very minor increasing effects with the increasing values of $H_{a}$. Figure 8 depicts that $w$ is increased with the increase of $R$.



Figure 4. Primary velocity distribution $u$ for different values of $H_{a}$.

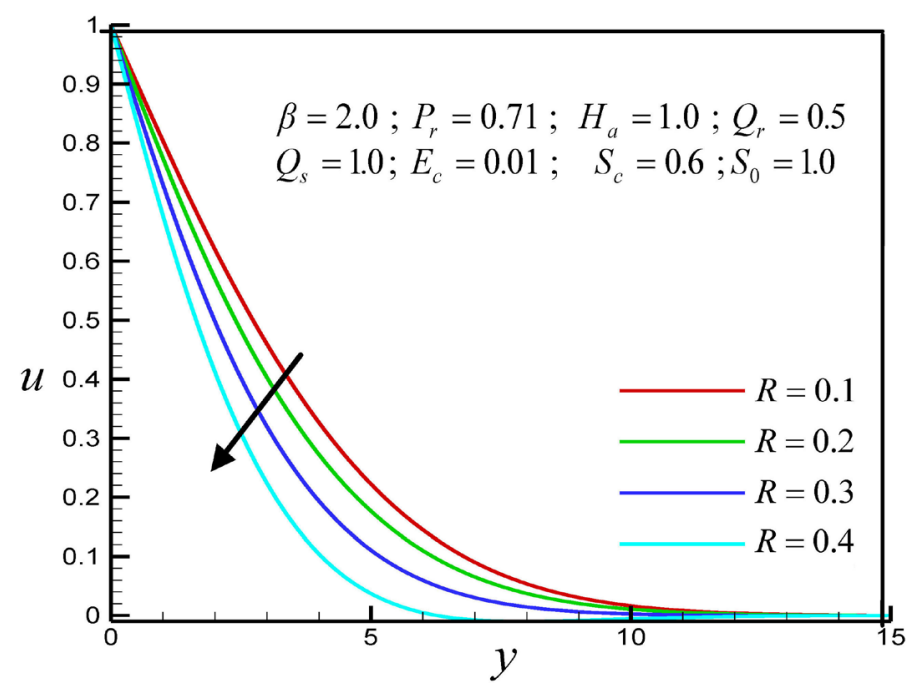

Figure 5. Primary velocity distribution $u$ for different values of $R$. 


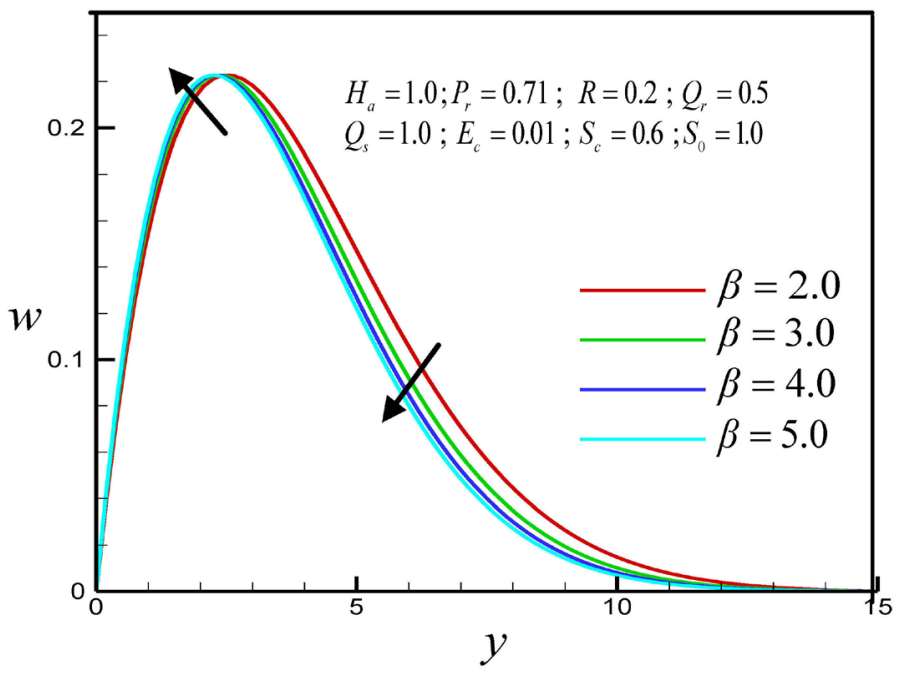

Figure 6. Secondary velocity distribution $w$ for different values of $\beta$.

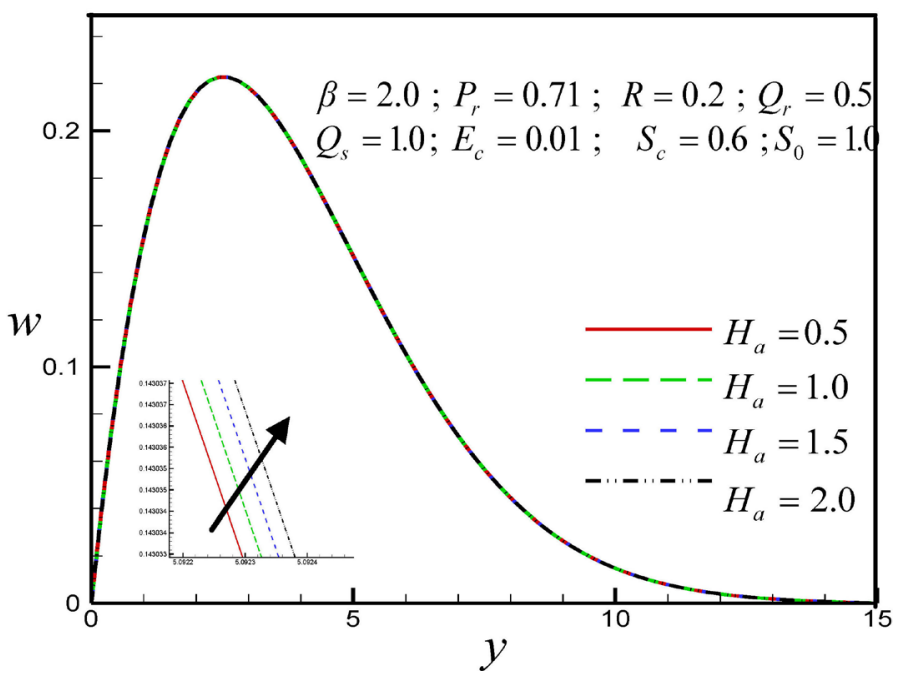

Figure 7. Secondary velocity distribution $w$ for different values of $H_{a}$.

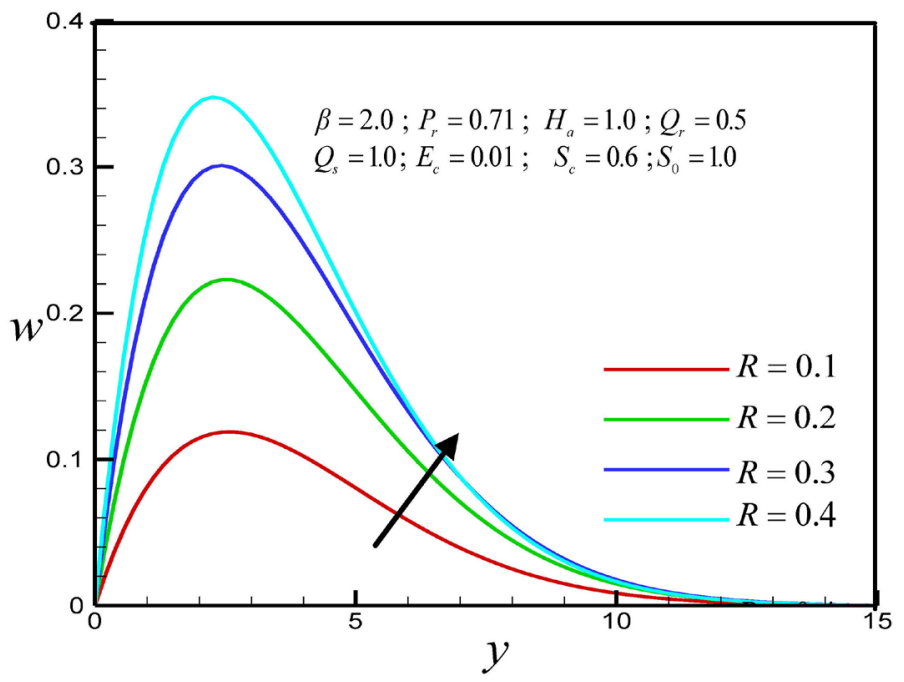

Figure 8. Secondary velocity distribution $w$ for different values of $R$. 


\subsection{Temperature Distribution}

Figure 9 is displayed that the rising values of the Eckert number $\left(E_{c}\right)$ lead to raise the fluid temperature. For the influence of $P_{r}$ the temperature $\theta$ is decreased, it is depicted in Figure 10. It is evident from Figure 11 that the effect of $Q_{s}$, the temperature $\theta$ is decreased.

\subsection{Concentration Distribution}

It is found from Figure 12 that near the plate the concentration distributions has an increasing effect with the increase of $Q_{s}$, thereafter it has very minor reverse effects. But Figure 13 demonstrates the effect of Sorret number on the concentration profile is increased.

\subsection{Local and Average Skin Friction}

It is mentioned that the figures (a) and (b) of Figures 14-16 refer to the local

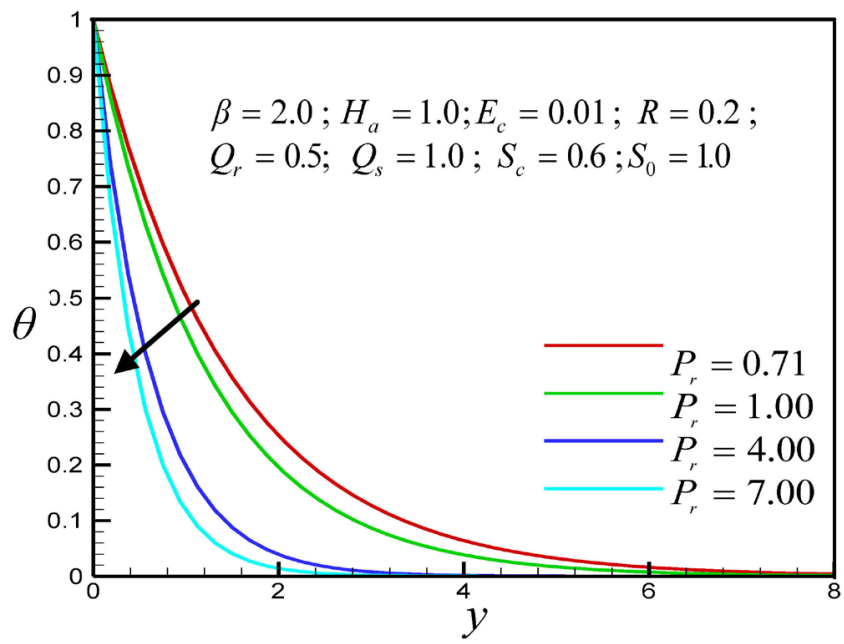

Figure 9. Temperature distribution $\theta$ for different values of $P_{r}$



Figure 10. Temperature distribution $\theta$ for different values of $Q_{s}$. 


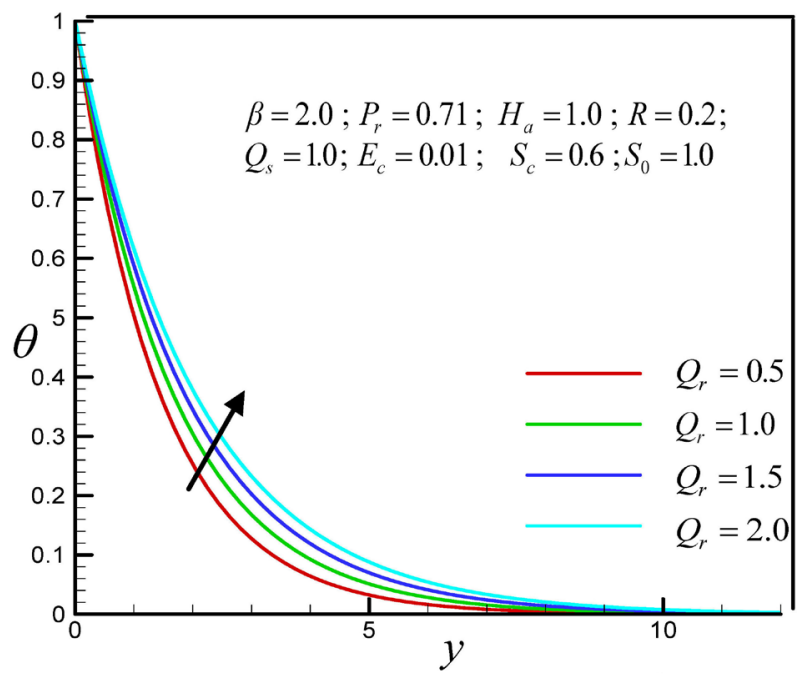

Figure 11. Temperature distribution $\theta$ for different values of $Q_{r}$

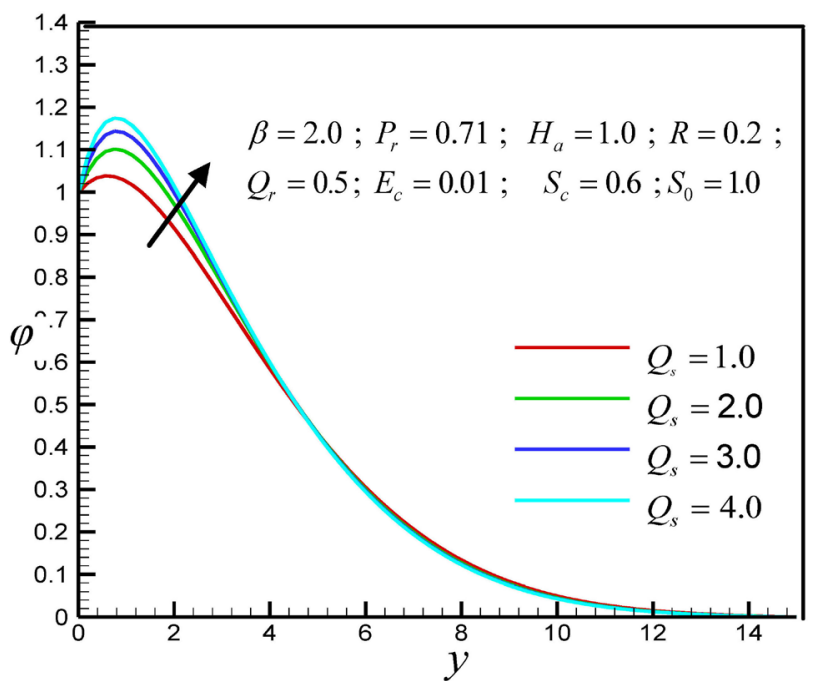

Figure 12. Concentration distribution $\varphi$ for different values of $Q_{s^{*}}$

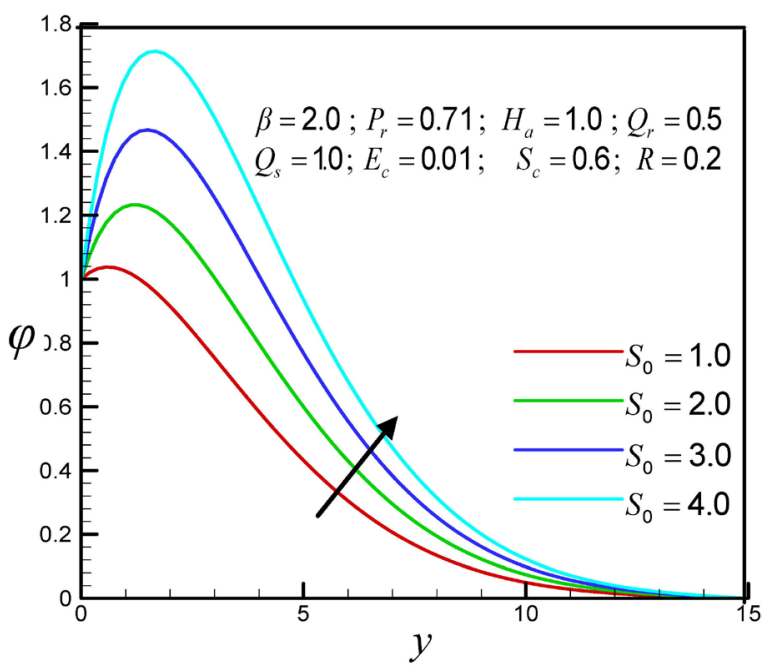

Figure 13. Concentration distribution $\varphi$ for different values of $S_{0}$. 


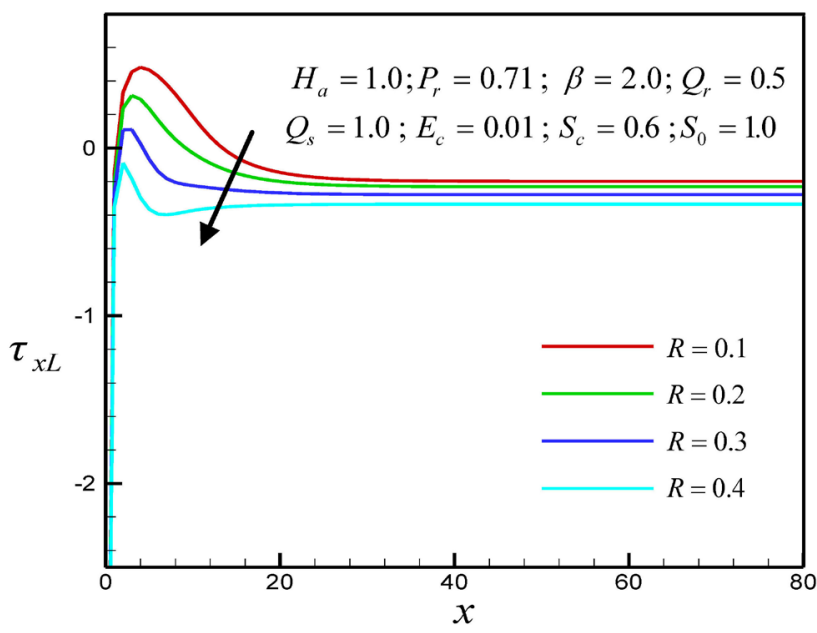

(a)

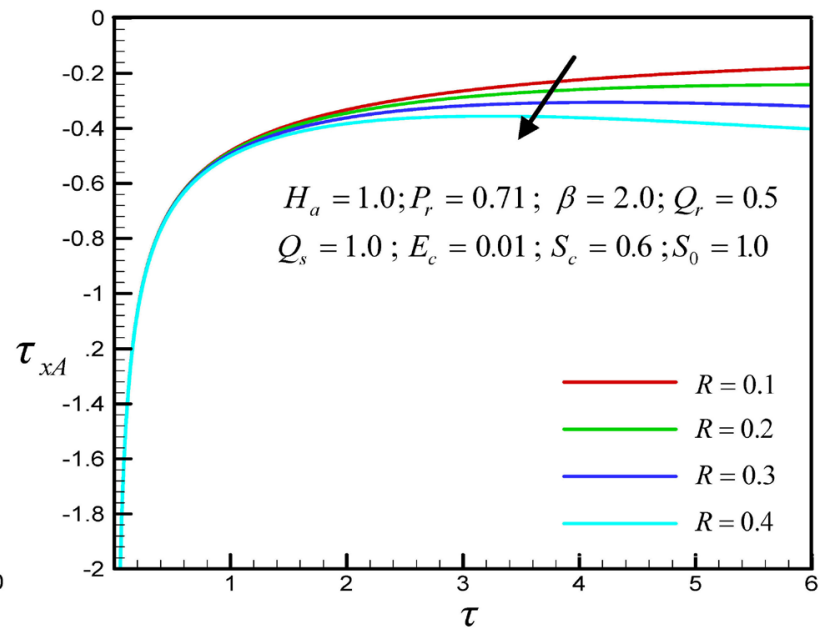

(b)

Figure 14. (a) Local shear stress $\tau_{x L}$ against $R$; (b) Average shear stress $\tau_{x A}$ against $R$.

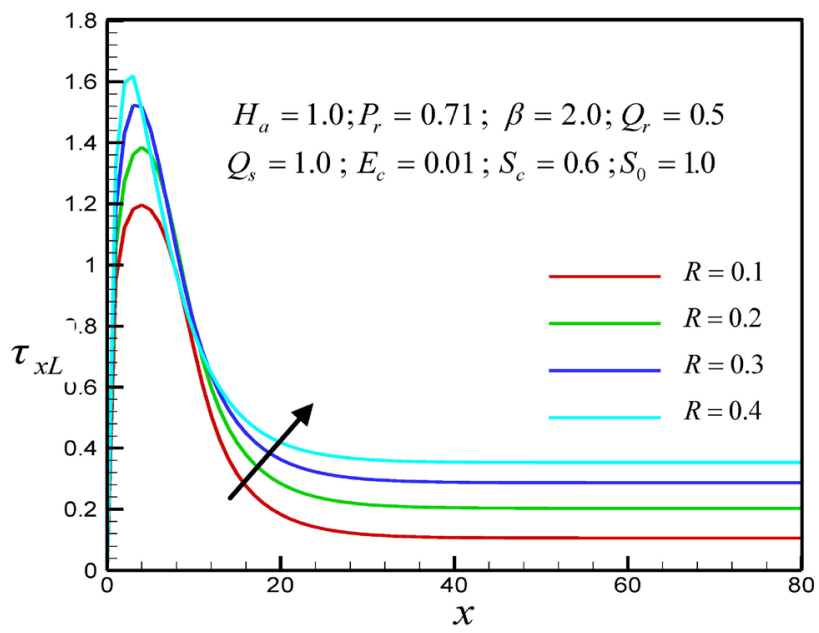

(a)

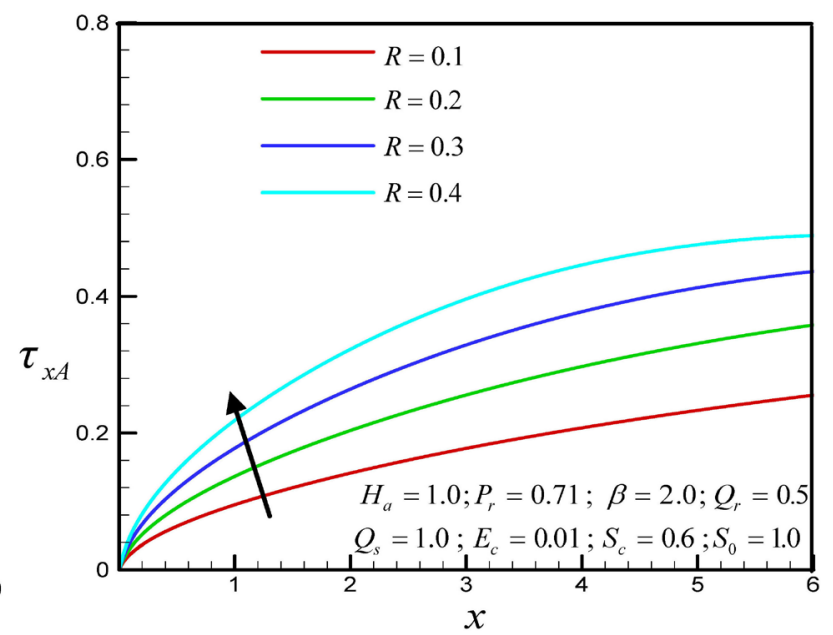

(b)

Figure 15. (a) Local shear stress $\tau_{z L}$ against $R$; (b) Average shear stress $\tau_{z A}$ against $R$.

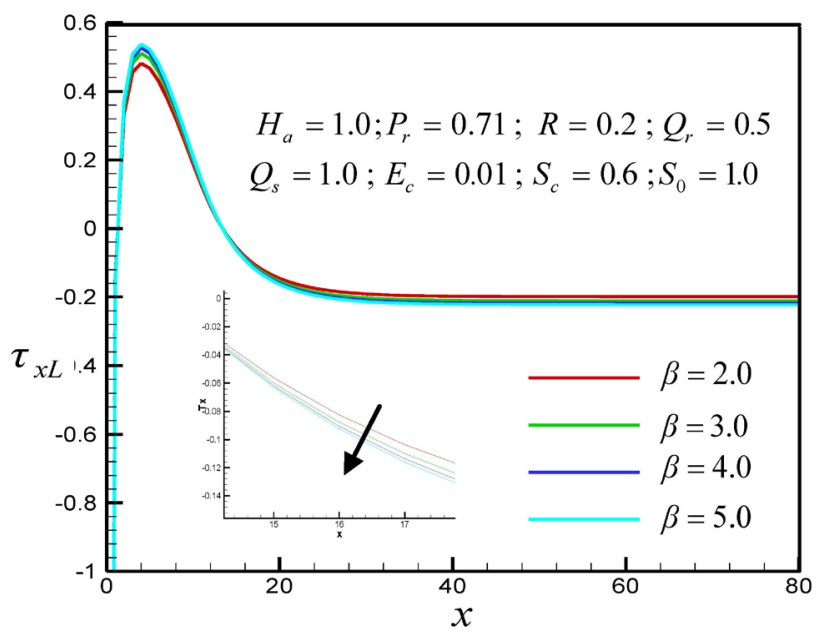

(a)

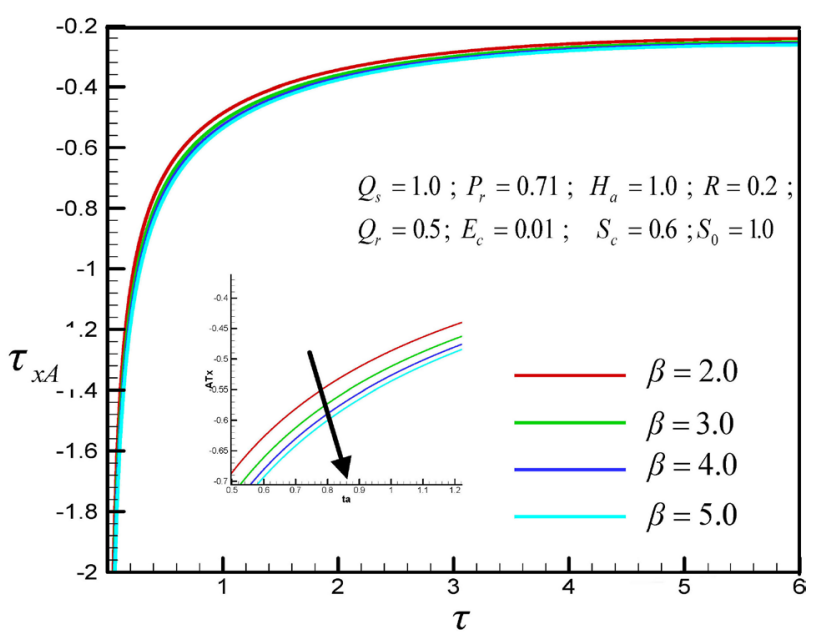

(b)

Figure 16. (a) Local shear stress $\tau_{x L}$ against $\beta$; (b) Average shear stress $\tau_{x A}$ against $\beta$. 



It is observed from Figure 14(a) \& Figure 14(b) that the local (and average) primary shear stresses both are decreases with the increase of $R$. But for secondary velocity distribution, local and average shear stresses both are increases with $R$, which is shown in Figure 15(a) \& Figure 15(b). The effects of Casson parameter on the local and average primary shear stresses have shown in Figure 16(a) \& Figure 16(b). Both figures have shown a very minor decreasing effect with the increases of $\beta$.

\subsection{Local and Average Nusselt Number and Sherwood Number}

Here Figure 17(a) \& Figure 17(b) refer to the influence of the heat source parameter on the Local (and average) Nusselt number. It has sheared that $N u_{L}$ and $N u_{A}$ both increase with the increase of $Q_{S}$. But the figures (a) and (b) of Figure 18 \& Figure 19 depict the local (and average) Sherwood number $S h_{L}$

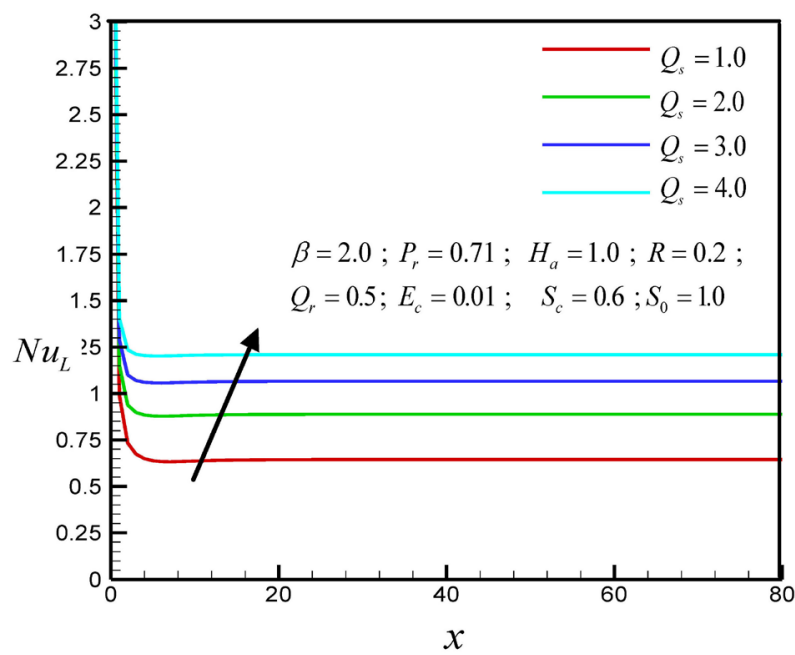

(a)

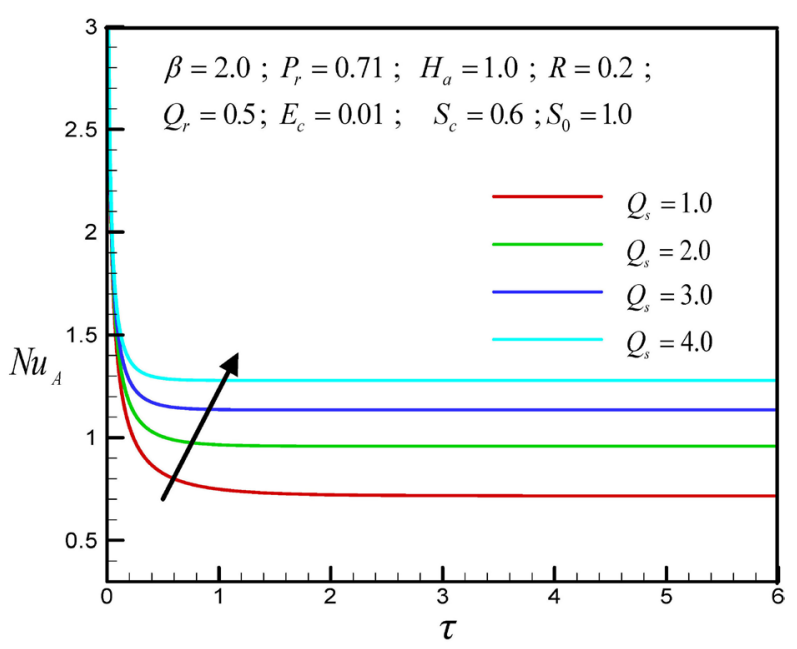

(b)

Figure 17. (a) Local Nusselt number $N u_{L}$ against $Q_{s}$; (b) Average Nusselt number $N u_{A}$ against $Q_{s}$.

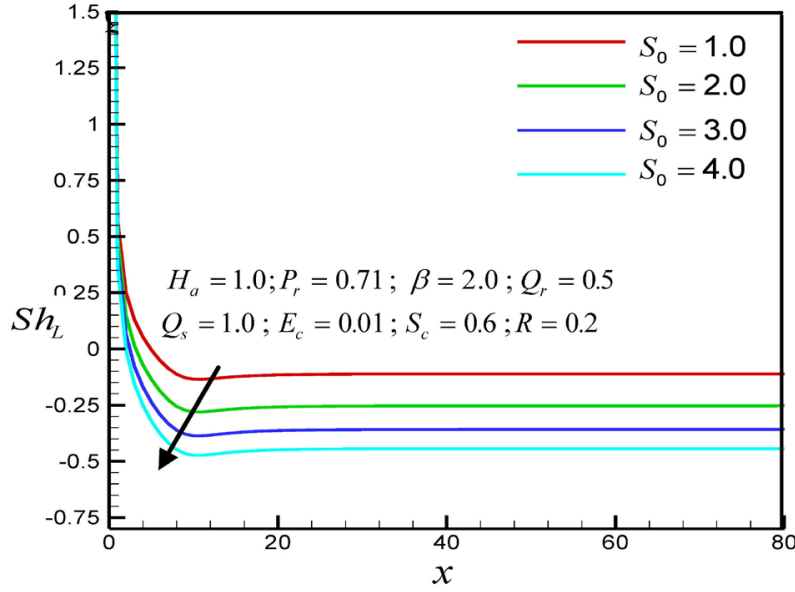

(a)

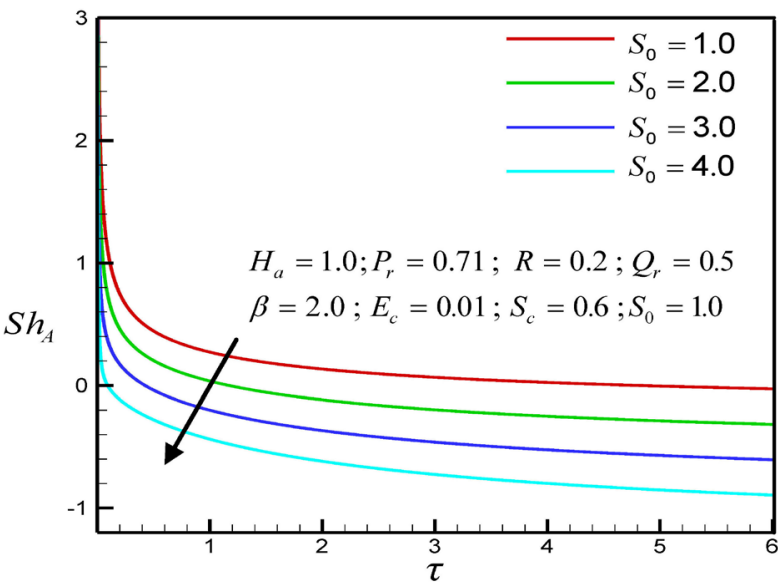

(b)

Figure 18. (a) Local Sherwood number $S h_{L}$ against $S_{0}$; (b) Average Sherwood number $S h_{A}$ against $S_{0}$. 


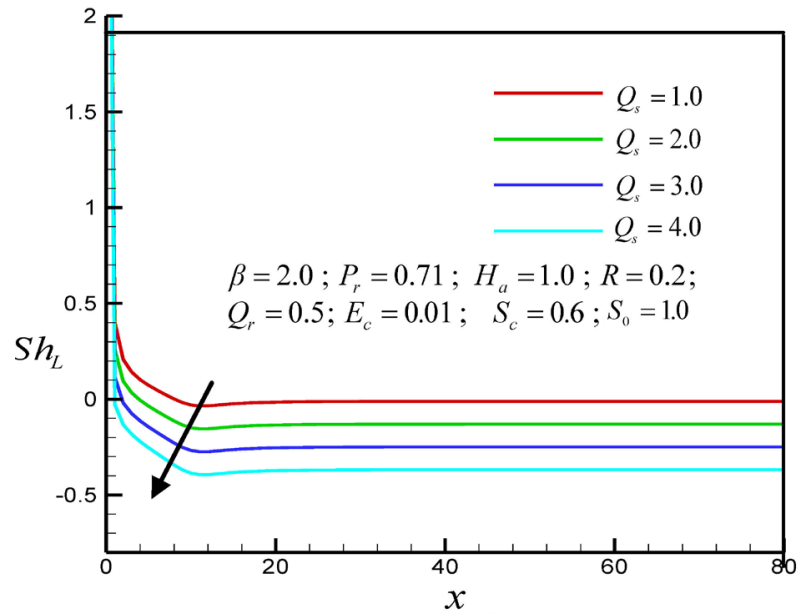

(a)

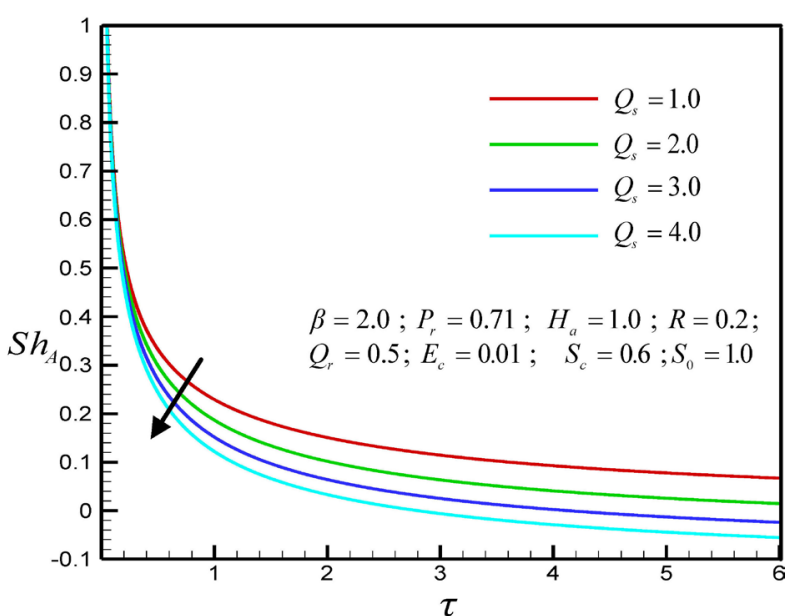

(b)

Figure 19. (a) Local Sherwood $S h_{L}$ number against $Q_{s}$; (b) Average Sherwood number $S h_{A}$ against $Q_{s}$.

(and $\left.S h_{L}\right)$ respectively. It is noticed in all figures, $\left(S h_{L}\right.$ and $\left.S h_{A}\right)$ both decrease with the increase of $S_{0}$ and $Q_{s}$ respectively.

\section{Conclusions}

The impulsively started horizontal Riga plate with rotation of unsteady Casson fluid flow has been discussed. The influence of various values of the Rotational parameter, modified Hartmann number, Prandtl number, Radiative parameter, Eckert number, Heat source parameter, Schmidt number and the Soret number has been analyzed. The non-linear coupled governing equations are solved numerically and the main findings can be summarized as follows:

- The primary velocity $u$ increases with the increase of $H_{a}$, while it decreases with the increase of $\beta$ and $R$.

- The secondary velocity $w$ rises with the increase of $R$ and $H_{a}$, while it decreases with the increase of $\beta$.

- The fluid temperature $\theta$ is increased with the increase of $Q_{r}$ but it decreases with the increase of $P_{r}$ and $Q_{s}$.

- The concentration $\phi$ rises for the increasing values of $Q_{s}$ and $S_{0}$.

- $\tau_{x L}$ (or $\tau_{x A}$ ) is decreased with increase of $R$ and $\beta$, while $\tau_{z L}$ (or $\tau_{z L}$ ) is increased with increase of $R$ and $\beta$. On the other hand $N u_{L}$ (or $N u_{A}$ ) is increased with increase of $Q_{s}$, while local (or average) Sherwood number is decreased with the influence of $S_{0}$ and $Q_{s}$.

\section{Conflicts of Interest}

The authors declare no conflicts of interest regarding the publication of this paper.

\section{References}

[1] Gailitis, A. and Leilausis, O. (1961) On a Possibility to Reduce the Hydro Dynamical Resistance of a Plate in an Electrode. Applied Magnetohydrodynamics, 12, 143-146. 
[2] Anjum, A., Mir, N.A., Farooq, M., Khan, M.I. and Hayat, T. (2018) Influence of Thermal Stratification and Slip Conditions on Stagnation Point Flow towards Variable Thicked Riga Plate. Results in Physics, 9, 1021-1030. https://doi.org/10.1016/j.rinp.2018.02.069

[3] Ahmed, A., Asghar, S. and Afzal, S. (2016) Flow of Nanofluid Past a Riga Plat. Journal of Magnetism and Magnetic Materials, 420, 44-48. https://doi.org/10.1016/j.jmmm.2015.11.043

[4] Wahidunnisa, L., Subbarayudu, K. and Suneetha, S. (2016) Effect of Viscous Dissipation over a Riga Plate in a Nano Fluid with Heat Source/Sink: A Numerical Study. International Journal of Technical Innovation in Modern Engineering \& Science, 4, 1124.

[5] Hayat, T., Abbas, T., Ayub, M., Faroq, M. and Alsaedi, A. (2016) Flow of Nanofluid Due to Convectively Heated Riga Plate with Variable Thickness. Journal of Molecular Liquids, 222, 854-862. https://doi.org/10.1016/j.molliq.2016.07.111

[6] Pantokratorasans, A. and Magyari, E. (2009) MHD Free-Convection Boundary Layer Flow from a Riga Plate. Journal of Engineering Mathematics, 64, 303-315. https://doi.org/10.1007/s10665-008-9259-6

[7] Pantokratoras, A. (2011) The Blasius and Sakiadis Flows along a Riga-Plate. Progress in Computational Fluid Dynamics. An International Journal, 11, 329-333. https://doi.org/10.1504/PCFD.2011.042184

[8] Iqbal, Z., Azhar, E., MEhmood, Z. and Maraj, E.N. (2018) Unique Outcomes of Internal Heat Generation and Thermal Deposition on Viscous Dissipative Transport of Visco Plastic Fluid over a Riga Plate. Communications in Theoretical Physics, 69, 68-76. https://doi.org/10.1088/0253-6102/69/1/68

[9] Eldabe, N.T.M. and Salwa, M.G.E. (1995) Heat Transfer of MHD Non-Newtonian Casson Fluid Flow between Two Rotating Cylinders. Journal of the Physical Society of Japan, 64, 41-64.

[10] Attia, H.A. and Sayed-Ahmed, M.E. (2006) Hydrodynamic Impulsively Lid-Driven Flow and Heat Transfer of a Casson Fluid. Tamkang Journal of Science and Engineering, 9, 195-204.

[11] Hayat, T., Shehzad, S.A. and Alsaedi, A. (2012) Soret and Dufour Effects on Magnetohydrodynamic (MHD) Flow of Casson Fluid. Applied Mathematics and Mechanics (English Edition), 33, 1301-1312.

https://doi.org/10.1007/s10483-012-1623-6

[12] Ramesh, K. and Devakar, M. (2015) Some Analytical Solutions for Flows of Casson Fluid with Slip Boundary Conditions. Ain Shams Engineering Journal, 6, 967-975. https://doi.org/10.1016/j.asej.2015.02.007

[13] Nandeppanavar, M.M., Veena, P.H. and Deshapande, V.H. (2016) Heat Transfer of MHD Flow of Casson Fluid Due to Stretching Sheet with PST and PHF Heating Conditions. Chemical and Process Engineering Research, 45, 39-49.

[14] Raju, C.S.K., Sandeep, N., Sugunamma, V., Babu, M.J. and Reddy, J.R. (2016) Heat and Mass Transfer in Magnetohydrodynamic Casson Fluid over an Exponentially Permeable Stretching Surface. Engineering Science and Technology, an International Journal, 19, 45-52. https://doi.org/10.1016/j.jestch.2015.05.010

[15] EswaraRao, M. and Sreenadh, S. (2017) MHD Flow of a Casson Fluid over an Exponentially Inclined Permeable Stretching Surface with Thermal Radiation, Viscous Dissipation and Chemical Reaction. Global Journal of Pure and Applied Mathematics, 13, 7529-7548.

[16] Saidulu, N. and Venkata Lakshmi, A. (2016) Slip Effects on MHD Flow of Casson 
Fluid over an Exponentially Stretching Sheet in Presence of Thermal Radiation, Heat Source/Sink and Chemical Reaction. European Journal of Advances in Engineering and Technology, 3, 47-55.

[17] Pramanik, S. (2014) Casson Fluid Flow and Heat Transfer Past an Exponentially Porous Stretching Surface in Presence of Thermal Radiation. Ain Shams Engineering Journal, 5, 205-212. https://doi.org/10.1016/j.asej.2013.05.003

[18] Ahmad, A. (2019) Flow Control of Non-Newtonain Fluid Using Riga Plate: Reiner-Phillipoff and Powell-Eyring Viscosity Models. Journal of Applied Fluid Mechanics, 12, 127-133. https://doi.org/10.29252/jafm.75.253.28897

[19] Yucel, A. (1989) Mixed Convection Micropolar Fluid Flow over Horizontal Plate with Surface Mass Transfer. International Journal of Engineering Science, 27, 1593-1608. https://doi.org/10.1016/0020-7225(89)90153-5

[20] Rasool, G., Zhang, T. and Shafiq, A. (2019) Second Grade Nanofluidic Flow Past a Convectively Heated Vertical Riga Plate. Physica Scripta, 94, Article ID: 125212. https://doi.org/10.1088/1402-4896/ab3990 